\title{
Diagnosis and Treatment of Vascular Air Embolism
}

Marek A. Mirski, M.D., Ph.D., * Abhijit Vijay Lele, M.D., † Lunei Fitzsimmons, M.D., † Thomas J. K. Toung, M.D.‡

CME CME Program. After reading the article, go to http://www. asahq.org/journal-cme to take the test and apply for Category 1 credit. Complete instructions may be found in the $\mathrm{CME}$ section at the back of this issue.

Vascular air embolism is a potentially life-threatening event that is now encountered routinely in the operating room and other patient care areas. The circumstances under which physicians and nurses may encounter air embolism are no longer limited to neurosurgical procedures conducted in the "sitting position" and occur in such diverse areas as the interventional radiology suite or laparoscopic surgical center. Advances in monitoring devices coupled with an understanding of the pathophysiology of vascular air embolism will enable the physician to successfully manage these potentially challenging clinical scenarios. A comprehensive review of the etiology and diagnosis of vascular air embolism, including approaches to prevention and management based on experimental and clinical data, is presented. This compendium of information will permit the healthcare professional to rapidly assess the relative risk of vascular air embolism and implement monitoring and treatment strategies appropriate for the planned invasive procedure.

INTRAOPERATIVE vascular air embolism (VAE) was reported as early as the 19th century, in both pediatric and adult practice. Well over 4,000 articles have been published during the past $30 \mathrm{yr}$ alone, providing ample resonance to the ubiquity and seriousness of this vascular event. Perhaps the most striking feature accumulated during this period is the myriad of clinical circumstances in which VAE may present itself, a result primarily of the increased technological complexity and invasiveness of modern therapeutics. Most episodes of VAE are likely preventable. This article provides a systematic review of the pathophysiology and clinical presentation of this acute phenomenon, as well as an in-depth analysis and algorithms for favorable methods of detection, prevention, and treatment.

Vascular air embolism is the entrainment of air (or

\footnotetext{
* Associate Professor, † Fellow in Anesthesiology, $\ddagger$ Professor.

Received from the Neurosciences Critical Care Division, Department of Anesthesiology and Critical Care Medicine, Johns Hopkins Medical Institutions, Baltimore, Maryland. Submitted for publication November 24, 2003. Accepted for publication August 23, 2006. Support was provided solely from institutional and/or departmental sources.

Address correspondence to Dr. Mirski: Department of Anesthesiology and Critical Care Medicine, 600 North Wolfe Street, Meyer Building 8-140, Baltimore, Maryland 21287. mmirski@jhmi.edu. Individual article reprints may be accessed at no charge through the Journal Web site, www.anesthesiology.org.
}

exogenously delivered gas) from the operative field or other communication with the environment into the venous or arterial vasculature, producing systemic effects. The true incidence of VAE may be never known, much depending on the sensitivity of detection methods used during the procedure. In addition, many cases of VAE are subclinical, resulting in no untoward outcome, and thus go unreported. Historically, VAE is most often associated with sitting position craniotomies (posterior fossa). Although this surgical technique is a high-risk procedure for air embolism, other recently described circumstances during both medical and surgical therapeutics have further increased concern about this adverse event. Conditions during which air embolism has been documented have substantively broadened, and much of the credit is owed to Albin et al. ${ }^{1-4}$ for their description of the pathophysiology during a variety of surgical procedures. Not only does the historic modus operandi of a gravitational gradient remain a concern, but we must now as well be suspicious of VAE during modern procedures where gas may be entrained under pressure, both within the peritoneal cavity or via vascular access. Hence, it is imperative for anesthesiologists to be aware of the causes of VAE, its morbidity, diagnostic considerations, treatment options, and adoption of practice patterns that best lead to the prevention of this potentially fatal condition.

\section{Pathophysiology}

The two fundamental factors determining the morbidity and mortality of VAE are directly related to the $\mathrm{vol}$ ume of air entrainment and rate of accumulation. When dealing simply with air being suctioned by a gravitational gradient, these variables are mainly impacted by the position of the patient and height of the vein with respect to the right side of the heart. Experimental studies have been conducted using several animal models to assess the volume of VAE necessary to provoke circulatory collapse. Lethal volumes of air entrained as an acute bolus have been concluded to be approximately $0.5-$ $0.75 \mathrm{ml} / \mathrm{kg}$ in rabbits ${ }^{5}$ and $7.5-15.0 \mathrm{ml} / \mathrm{kg}$ in dogs. ${ }^{6,7}$ Translating such data into the adult human would be difficult, if not for some parallel confirmation from the clinical literature. From case reports of accidental intravascular delivery of air, ${ }^{8,9}$ the adult lethal volume has 
been described as between 200 and $300 \mathrm{ml}$, or 3-5 $\mathrm{ml} / \mathrm{kg}$. The authors of these reports suggest that the closer the vein of entrainment is to the right heart, the smaller the required lethal volume is.

The rate of air entrainment is also of importance, because the pulmonary circulation and alveolar interface provide for a reservoir for dissipation of the intravascular gas. As early as 1969 , it was shown by Flanagan et al. ${ }^{10}$ that a pressure decrease of $5 \mathrm{~cm} \mathrm{H}_{2} \mathrm{O}$ across a 14-gauge needle (internal diameter of $1.8 \mathrm{~mm}$ ) is capable of transmitting approximately $100 \mathrm{ml}$ of air/s. This rate of entrainment easily exceeds lethal accumulation if not terminated immediately. Such data highlights the risk of catastrophic VAE in many vascular procedures performed in patients, because the luminal size is well within the diameter of commonly placed hardware. If entrainment is slow, the heart may be able to withstand large quantities of air despite entrainment over a prolonged period. As shown by Hybels,${ }^{11}$ dogs were able to withstand up to $1,400 \mathrm{ml}$ of air over a several-hour period.

Both volume and rate of air accumulation are dependent on the size of the vascular lumen as well as the pressure gradient. The risk of VAE is also present under circumstances that prevent the collapse of veins even at modest decreases of pressure relative to that in the venous system (surgical dissection). Not only negative pressure gradients but also positive pressure insufflation of gas may present a serious VAE hazard. Injection of gas (or liquid-air mixtures), such as into the uterine cavity for separation of placental membrane or for a variety of laparoscopic procedures, poses a risk for VAE.

Early animal experiments indicated that VAE increases microvascular permeability. ${ }^{12}$ Embolization of the right ventricular chamber has been shown to induce pulmonary hypertension related to the release of endothelin 1 from the pulmonary vasculature. ${ }^{13}$ The microbubbles formed due to turbulent flow in the circulation precipitate platelet aggregation and the release of platelet activator inhibitor. This, in turn, may lead to systemic inflammatory response syndrome. ${ }^{14}$

These physical and chemical responses may cause injury to the pulmonary capillary network, leading to pulmonary edema. ${ }^{15-20}$ Another mechanism of lung injury includes toxic free radical damage. An argument has been made to attenuate pulmonary edema with high doses of steroids such as methylprednisone. ${ }^{21}$

Several pathophysiologic pathways may be elucidated after a substantive volume of air or gas entrainment. Which pathway is manifested is greatly dependent on the volume of gas accumulated within the right ventricle. If the embolism is large (approximately $5 \mathrm{ml} / \mathrm{kg}$ ), a gas air-lock scenario immediately occurs. There may be complete outflow obstruction from the right ventricle as failure from the inability to decompress the tension of the ventricular wall. This rapidly leads to right-sided heart failure and immediate cardiovascular collapse. With more modest volumes of VAE, the embolism may still result in significant right ventricular outflow obstruction, with an attendant decrease in cardiac output, hypotension, myocardial and cerebral ischemia, and even death. Even if the cardiac output remains above that required for adequate perfusion, the embolism may nonetheless impart significant and even lethal injury. Air entrainment into the pulmonary circulation may lead to pulmonary vasoconstriction, release of inflammatory mediators, bronchoconstriction, and an increase in ventilation/perfusion mismatch.

\section{Clinical Presentation}

Vascular air embolism may have cardiovascular, pulmonary, and neurologic sequelae. The spectrum of effects is dependent on the rate and entrained volume of VAE, as well as other two additional factors: whether the patient is spontaneously breathing, yielding negative thoracic pressure during respiratory cycle with facilitation of air entrainment, or under controlled positivepressure ventilation. An informative summary of the common relation between clinical presentation and acute embolism volume is presented in figure 1 .

Cardiovascularly, tachyarrhythmias are common, and the electrocardiogram demonstrates a right heart strain pattern as well as ST-T changes. Myocardial ischemia may be observed, and in animal studies, peaking of the $P$ wave is seen in the earlier stages. Blood pressure decreases as cardiac output falters. Pulmonary artery pressures increase as a consequence of increased filling pressures and reduction of cardiac output. The central venous pressure measurements also increase as a secondary effect of right heart failure, and jugular venous distension may be noted. As hypotension increases, shock ensues.

Pulmonary symptoms in awake patients include acute dyspnea, continuous coughing, ${ }^{22}$ urgent complaints of breathlessness, ${ }^{23}$ lightheadedness, chest pain, and a sense of "impending doom." The common response of gasping for air as a consequence of dyspnea forces a further reduction in intrathoracic pressure, frequently resulting in more air entrainment. Pulmonary signs of VAE include rales, wheezing, and tachypnea. During anesthesia with respiratory monitoring, decreases in end-tidal carbon dioxide $\left(\mathrm{ETCO}_{2}\right)$, and both arterial oxygen saturation $\left(\mathrm{SaO}_{2}\right)$ and tension $\left(\mathrm{PO}_{2}\right)$, along with hypercapnia, may be detected. Invasive cardiac monitoring commonly increases pulmonary airway pressure.

The central nervous system may be affected by VAE by one of two mechanisms. Cardiovascular collapse secondary to reduced cardiac output (from output obstruction, right ventricular failure, or myocardial ischemia) rapidly results in cerebral hypoperfusion. In mild form, acute 


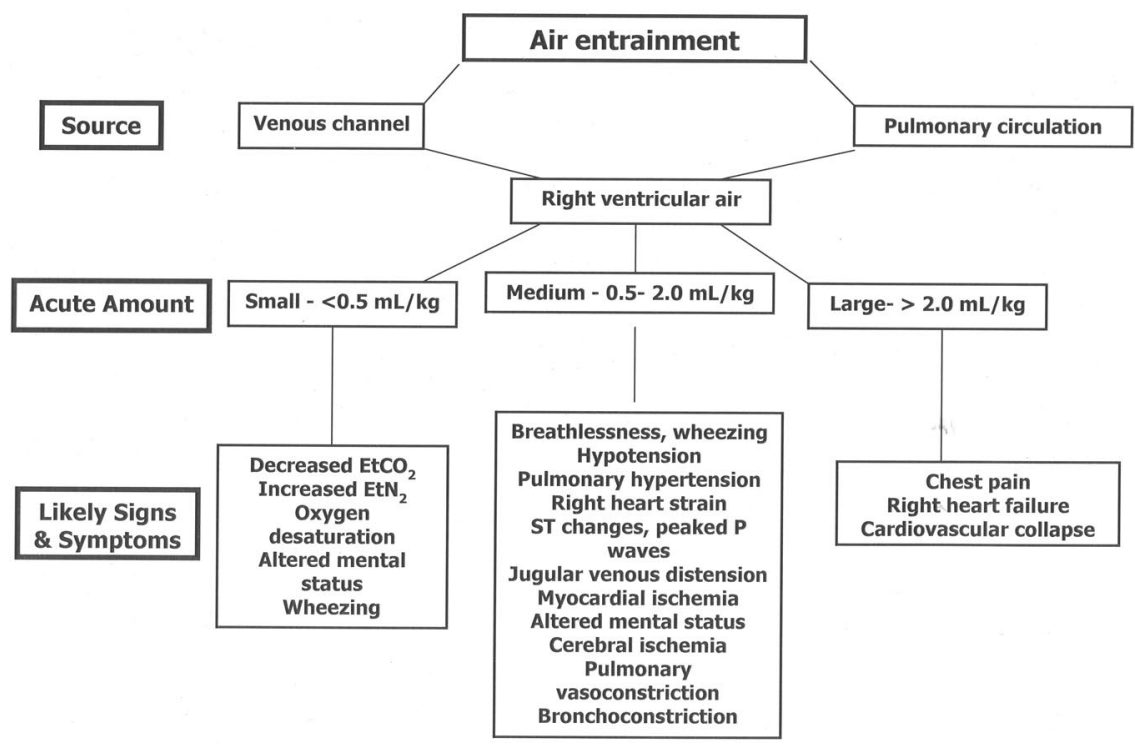

Fig. 1. Adverse sequelae from air embolism are dependent principally on the volume of air, as well as the rate of entrainment. Small acute volumes are often well tolerated, whereas larger volumes have substantial effects predominating on the cardiovascular, pulmonary, and cerebral organ systems. ETCO $_{2}=$ end-tidal carbon dioxide; $\mathbf{E T N}_{2}=$ end-tidal nitrogen. altered mental status presents, but focal deficits related to cerebral hyperemia and cerebral edema leading to frank coma quickly follow. Second, direct cerebral air embolism may occur via a patent foramen ovale, a residual defect that is present in approximately $20 \%$ of the adult population. Mental status changes postoperatively should raise the suspicion of cerebral ischemia secondary to air embolism in at-risk individuals.

\section{Clinical Etiology}

Improvements in monitoring such as measurement of $\mathrm{ETCO}_{2}$ and end-tidal nitrogen $\left(\mathrm{ETN}_{2}\right)$ have helped to confirm VAE as a relatively common event during surgical procedures. The breadth of clinical circumstances in which air or gas embolism poses a substantial risk became ever more appreciated. Recent technological advances whereby air is delivered by positive pressure within the abdominal cavity or via vascular access further increase the risk of VAE. It is no longer safe to presume that lack of a negative-pressure system eliminates potential embolism. Common surgical procedures with risk for $\mathrm{VAE}^{24-64}$ are listed in table 1 . The gravitational gradients may exist not only during surgery, but whenever the vasculature is introduced to relative negative pressure (i.e., suction effect). Table 2 summarizes nonsurgical clinical incidents documenting gas embolization. ${ }^{65-76}$ Relatively novel etiologies include air embolism during eye surgery, home infusion therapy in children, ${ }^{68}$ placement of deep brain stimulators, ${ }^{37,38}$ lumbar puncture ${ }^{73}$ contrast-enhanced computed tomographic imaging, ${ }^{71,72}$ and radial artery catheterization. ${ }^{67}$

Gas embolism may occur not only in an anterograde venous course, as is most typical, but also via epidural spaces, via tissue planes, and in a retrograde fashion either arterially or by venous channels. Such paths may result in air found in unusual compartments-not simply via the vena cava to the heart and into the pulmonary circulation. An excellent visual example is provided by a case report by Alper et al. ${ }^{77}$ After penetrating chest wound trauma and documented tension pneumothorax, the 8-yr-old patient was noted by brain computed tomographic imaging to have massive air densities within the cerebral circulation. It was unclear whether the air found its way there by passage via the pulmonary veins or by direct injury to the greater thoracic arterial vessels. There are also numerous reports of a patent foramen ovale permitting air directly to the cerebral circulation. ${ }^{27,78-82}$

What can we learn from the voluminous reports of air/gas embolism? First, the clinical conditions do follow certain simple patterns, and appreciation of may alter our plan of procedure, suggest additional monitoring, or make preparations for early intervention. The clinical procedures listed in table 3 can be highlighted as air embolism risks. Of surgical procedures, neurosurgical cases remain the highest risk as a consequence of the following:

- Elevated positioning of wound relative to the heart - Numerous large, noncompressed, venous channels in the surgical field-especially involving cervical procedures and craniotomies that breach the dural sinuses

- Such elements may occur in other surgeries in which patient positioning yields a similar gravitational threat (lateral decubitus thoracotomy, genitourinary surgeries in the Trendelenburg position) or a high degree of vascularity (tumors, malformations) or compromised vessels (trauma) are present. The potential for VAE is commonly not considered in laparoscopic surgery and cesarean delivery, despite the reported incidence risk of greater than $50 \%$ during each surgical procedure (table 1). Indeed, each procedure has been associated 
Table 1. Surgical Procedures Associated with Vascular Air Embolism

\begin{tabular}{|c|c|}
\hline Procedure & References and Known Incidence \\
\hline \multicolumn{2}{|l|}{ Neurosurgical } \\
\hline Sitting position craniotomies & $\begin{array}{l}\text { Harrison et al. }{ }^{24}(9.3 \%), \text { Bithal et al. }{ }^{25}(27.4 \%) \text {, } \\
\text { Losasso et al. }{ }^{26}(43 \%)\end{array}$ \\
\hline Posterior fossa procedures & Papadopoulos et al. ${ }^{27}(76 \%)$ \\
\hline Craniosynostosis repair & Faberowski et al. ${ }^{28}$ (8\%), Tobias et al. ${ }^{29}$ (82.6\%) \\
\hline Cervical laminectomy & Lopez et al. ${ }^{30}(23 \%)$ \\
\hline Spinal fusion & Latson $^{31}(10 \%)$ \\
\hline Peripheral denervation & Girard et al. ${ }^{35}(2 \%)$ \\
\hline Torticollis corrective surgery & Lobato et al. ${ }^{36}$ \\
\hline Deep brain stimulator placement & Moitra et al., ${ }^{37}$ Deogaonkar et al.. ${ }^{38}$ \\
\hline \multicolumn{2}{|l|}{ Neck procedures } \\
\hline Radical neck dissection & Longenecker ${ }^{39}(1-2 \%)$ \\
\hline Thyroidectomy & Chang et al. ${ }^{40}(2 \%)$ \\
\hline \multicolumn{2}{|l|}{ Ophthalmologic procedures } \\
\hline Eye surgery & Ledowski et al. ${ }^{41}$ \\
\hline \multicolumn{2}{|l|}{ Cardiac surgery } \\
\hline Coronary air embolism & Abu-Omar et al. ${ }^{42}$ \\
\hline \multicolumn{2}{|l|}{ Orthopedic procedures } \\
\hline Total hip arthroplasty & Spiess et al. ${ }^{43-46}$ (57\%) \\
\hline Arthroscopy & Faure et al. ${ }^{47}$ \\
\hline \multicolumn{2}{|l|}{ Thoracic procedures } \\
\hline Thoracocentesis & Diamond et al. ${ }^{48}$ \\
\hline Blast injuries, excessive positive pressure, open chest wounds & Campbell and Kerridge, ${ }^{49}$ Gotz et al. ${ }^{50}$ \\
\hline \multicolumn{2}{|l|}{ Obstetric-gynecologic procedures } \\
\hline Cesarean delivery & Lew et al. ${ }^{51-53}(11-97 \%)$ \\
\hline Laparoscopic procedures, Rubin insufflation procedures, vacuum abortion & Bloomstone et al., ${ }^{54}$ Imasogie et al. ${ }^{55}$ \\
\hline \multicolumn{2}{|l|}{ Urology } \\
\hline Urology-prostatectomy & Memtsoudis et al., ${ }^{56}$ Jolliffe et al., ${ }^{57}$ Razvi et al. ${ }^{58}$ \\
\hline \multicolumn{2}{|l|}{ Gastrointestinal surgery } \\
\hline Laparoscopic cholecystectomy & Derouin et al. ${ }^{59}$ (69\%), Scoletta et al., ${ }^{60}$ Bazin et al. ${ }^{61}$ \\
\hline Gastrointestinal endoscopy & Nayagam, ${ }^{62}$ Green and Tendler ${ }^{63}$ \\
\hline Liver transplantation & Souron et al. ${ }^{64}$ \\
\hline
\end{tabular}

with intraoperative death as a direct consequence of air embolism. ${ }^{83-87}$ The risk of air embolism during cesarean delivery seems to be a frequent finding when investigated by $\mathrm{ETN}_{2}$ or Doppler ultrasonography, although in some cases, the presence of abnormal Doppler signals may reflect turbulent venous return rather than air embolism. ${ }^{51}$ The period in which risk may be highest is when the uterus is exteriorized. ${ }^{88}$ Patient positioning to reverse Trendelenburg seems not to reduce the risk. ${ }^{51}$ During laparoscopic surgery, evidence points to the prerequisite of inadvertent open vascular channels through surgical manipulation as a risk for VAE rather than simply a complication of insufflation. $^{89-90}$

Table 2. Examples of Nonoperative Procedures Associated with Vascular Air Embolism

\begin{tabular}{|c|c|}
\hline Procedure & References \\
\hline \multicolumn{2}{|l|}{ Direct vascular } \\
\hline Central venous access related & Flanagan et al., ${ }^{10}$ Vesely, ${ }^{65}$ Ely and Duncan ${ }^{66}$ \\
\hline Radial artery catheterization & Dube et al. ${ }^{67}$ \\
\hline Parenteral nutrition therapy & Laskey et al. ${ }^{68}$ \\
\hline Interventional radiology & Keiden et al., ${ }^{45}$ Hetherington and McQuillan ${ }^{46}$ \\
\hline \multicolumn{2}{|l|}{ Pain management procedures } \\
\hline Epidural catheter placement (loss of resistance to air technique) & Panni et al., ${ }^{69}$ MacLean and Bachman ${ }^{70}$ \\
\hline \multicolumn{2}{|l|}{ Diagnostic procedures } \\
\hline Contrast-enhanced CT & Woodring and Fried ${ }^{71}$ \\
\hline Contrast-enhanced CT chest & Groell et al. ${ }^{72}$ \\
\hline Lumbar puncture & Karaosmanglu et al. ${ }^{73}$ \\
\hline Thoracentesis & Diamond et al. ${ }^{48}$ \\
\hline \multicolumn{2}{|l|}{ Hemoperfusion } \\
\hline Intraaortic balloon rupture & Cruz-Flores et al. ${ }^{74}$ \\
\hline Rapid blood cell infusion systems & Aldridge $\mathrm{e}^{75}$ \\
\hline Blood storage container & Yeakel $^{76}$ \\
\hline
\end{tabular}

$\mathrm{CT}=$ computed tomography. 
Table 3. Relative Risk of Air/Gas Embolism

\begin{tabular}{ll}
\hline Air/Gas Embolism Risk: Common Procedures & Relative Risk* \\
\hline Sitting position craniotomy & High \\
Posterior fossa/neck surgery & High \\
Laparoscopic procedures & High \\
Total hip arthroplasty & High \\
Cesarean delivery & High \\
Central venous access-placement/removal & High \\
Craniosynostosis repair & High \\
Spinal fusion & Medium \\
Cervical laminectomy & Medium \\
Prostatectomy & Medium \\
Gastrointestinal endoscopy & Medium \\
Contrast radiography & Medium \\
Blood cell infusion & Medium \\
Coronary surgery & Medium \\
Peripheral nerve procedures & Low \\
Anterior neck surgery & Low \\
Burr hole neurosurgery & Low \\
Vaginal procedures & Low \\
Hepatic surgery & Low \\
\hline
\end{tabular}

* Approximate expected reported incidences: high, > 25\%; medium, 5-25\%; low, $<5 \%$ (references per tables 1 and 2).

\section{Detection of Vascular Air Embolism}

Before the inclusion of multimonitoring technologies, the clinical diagnosis of VAE was dependent on direct observation of air suction in the surgical field, deduction from clinical events, or postmortum discovery of air in the vasculature or heart chambers. More recently, we rely predominantly on our real-time monitors, some of which are standard, and several specifically used for the purpose of detecting VAE. In general, the monitoring devices that are used should be sensitive, easy to use, and noninvasive. The selection of monitoring device should be predicated on the surgery performed, the position of the patient, the expertise of the anesthesiologist in using the device, and the overall medical condition of the patient.

The detection of an ongoing episode of VAE is a clinical diagnosis, taking into consideration the circumstances under which clinical alterations occur. There are specific circumstances where the diagnosis of VAE should be considered immediately in the differential diagnosis:

- Any unexplained hypotension or decrease in $\mathrm{ETCO}_{2}$ intraoperatively in cases that are performed in the reverse Trendelenburg position or in situations where there is exposure of venous vasculature to atmospheric pressure

- Patients undergoing insertion or removal of a central venous catheter who report shortness of breath during or shortly after completion of the procedure

- Patients undergoing cesarean delivery who have sustained hypotension and or hypoxia not explained by hypovolemia alone

There are few randomized case-control studies that have assessed the efficacy and the benefit of any monitoring for VAE. Nevertheless, incorporation of certain devices has approached a relative standard of practice. Hence, it would be difficult to demonstrate their benefit in a controlled investigation. In table 4 , specific monitoring modalities are listed in the descending order of sensitivity (in $\mathrm{ml} / \mathrm{kg}$ if established) and specificity of VAE detection, but not necessarily their utility or popularity. ${ }^{91}$

\section{Transesophageal Echocardiography}

This instrument is currently the most sensitive monitoring device for VAE, detecting as little as $0.02 \mathrm{ml} / \mathrm{kg}$ of air administered by bolus injection. ${ }^{92,93}$ It permits detection not only of venous macroemboli and microemboli, but also paradoxical arterial embolization that may result in ischemic cerebral complications. Notwithstanding, transesophageal echocardiography (TEE) has been said to be almost too sensitive, detecting virtually any amount of air in the circulation, most leading to no adverse sequelae. The counter argument is that the presence of any volume of air should alert the anesthesiologist to institute prophylactic measures, reducing the risk of further entrainment. Cardiac anesthesiologists frequently use TEE for intraoperative patient monitoring

Table 4. Comparison of Methods of Detection of Vascular Air Embolism

\begin{tabular}{|c|c|c|c|c|}
\hline Method of Detection & Sensitivity (ml/kg) & Availability & Invasiveness & Limitations \\
\hline TEE & High (0.02) & Low & High & Expertise required, expensive, invasive \\
\hline Precordial Doppler & High (0.05) & Moderate & None & Obese patients \\
\hline PA catheter & High (0.25) & Moderate & High & Fixed distance, small orifice \\
\hline TCD & High & Moderate & None & Expertise required \\
\hline $\mathrm{ETN}_{2}$ & Moderate $(0.5)$ & Low & None & $\mathrm{N}_{2} \mathrm{O}$, hypotension \\
\hline $\mathrm{ETCO}_{2}$ & Moderate (0.5) & Moderate & None & Pulmonary disease \\
\hline Oxygen saturation & Low & High & None & Late changes \\
\hline Direct visualization & Low & High & None & No physiologic data \\
\hline Esophageal stethoscope & Low (1.5) & High & Low & Late changes \\
\hline Electrocardiogram & Low (1.25) & High & Low & Late changes \\
\hline
\end{tabular}

$\mathrm{ETCO}_{2}=$ end-tidal carbon dioxide gas; $\mathrm{ETN}_{2}=$ end-tidal nitrogen gas; $\mathrm{N}_{2} \mathrm{O}=$ nitrous oxide; PA = pulmonary artery; TCD = transcranial Doppler; TEE = transesophageal echo. 
and also for detecting residual air when the patient is being weaned from bypass.

The major deterrents to TEE are that it is invasive, is expensive, and requires expertise and constant vigilance that may limit its use by a noncardiac anesthesiologist. A report by Himmelseher et al. ${ }^{94}$ in Germany noted the use of TEE as standard of practice in only $38 \%$ of patients undergoing intracranial procedures, compared with near uniformity of use of precordial Doppler ultrasound.

\section{Precordial Doppler Ultrasound}

The precordial Doppler is the most sensitive of the noninvasive monitors, capable of detecting as little as $0.25 \mathrm{ml}$ of air $(0.05 \mathrm{ml} / \mathrm{kg}){ }^{95}$ The Doppler probe (typically a 2 - to $5-\mathrm{mHz}$ device) can be placed on either the right or the left sternal border (second to fourth intercostal spaces) or, alternatively, between the right scapula and the spine. ${ }^{96}$ We have had good success in both adults and children using these landmarks. The probe is placed along the right heart border, to pick up signals from the right ventricular outflow tract. Generally, the positioning is confirmed by an injection or "bubble" test (injection of an air-agitated 10-ml bolus mixture of $1 \mathrm{ml}$ or less of air in $9 \mathrm{ml}$ saline). The bubble test is helpful in positioning the Doppler probe especially in obese patients.

The first discernible evidence of VAE is a change in the character and intensity of the emitted sound. The "washing machine" turbulent resonance of normal blood flow passing through the right cardiac chambers abruptly is superimposed by an erratic high-pitched swishing roar. Although it is generally easy to appreciate the audible transition, the anesthesiologist must pay close attention to the sounds throughout the case. With greater air entrainment, a more ominous "drum-like" or "mill wheel" murmur develops, signaling cardiovascular decompensation. The sound volume at which this device is used should be at a level appropriate to hear the audio signal above the din of the other operative instrumentation, and preferably kept constant throughout the period of use. Major impediments in the use of this device include sound artifacts during concurrent use of electrocautery, prone and lateral patient positioning, and morbid obesity. The combination use of a precordial Doppler probe along with a two-dimensional echo image may improve detection. ${ }^{97}$

\section{Transcranial Doppler Ultrasound}

Contrast-enhanced transcranial Doppler has been shown to be highly sensitive in the detection of a patent foramen ovale and has been used as a screening tool for patients undergoing high-risk procedures. The sensitivity of this method has been shown to increase with the use of the Valsalva maneuver. ${ }^{98}$ In comparison with TEE, contrast-enhanced transcranial Doppler has shown a sen- sitivity of $91.3 \%$, a specificity of $93.8 \%$, and an overall accuracy of $92.8 \% .^{99}$

\section{Pulmonary Artery Catheter}

A pulmonary artery catheter is a relatively insensitive monitor of air entrainment $(0.25 \mathrm{ml} / \mathrm{kg}),{ }^{91,95}$ being inferior to the precordial Doppler and far too invasive for a patient who has no other comorbidities requiring its use. The pulmonary artery catheter is of limited ability to withdraw air from its small caliber lumen. The use of the pulmonary artery catheter is thus restricted to those patients who have significant comorbidities that may benefit from its use as a monitoring tool for cardiac output or mixed venous saturation. Volk et al. ${ }^{100}$ have demonstrated the utility of an $8-\mathrm{MHz}$ probe introduced through the central venous catheter in pig studies to improve upon VAE detection and have claimed a $0.5-\mu 1$ sensitivity.

\section{End-tidal Nitrogen}

Not routinely available on all anesthesia monitors, $\mathrm{ETN}_{2}$ is the most sensitive gas-sensing VAE detection method, measuring increases in $\mathrm{ETN}_{2}$ as low as $0.04 \%{ }^{91,101}$ It has been shown that changes in $\mathrm{ETN}_{2}$ occur 30-90 s earlier than changes in $\mathrm{ETCO}_{2}{ }^{102}$ The sensitivity compares to or exceeds that of $\mathrm{ETCO}_{2}$ during large-bolus VAE but may be less sensitive during slower entrained volumes. ${ }^{103}$ Unfortunately, not all anesthetic monitors have the capability to measure $\mathrm{ETN}_{2}$, and this method is not useful if nitrous oxide is used as a carrier gas. The presence of $\mathrm{ETN}_{2}$ may also indicate air clearance from the pulmonary circulation prematurely, and the method is limited by hypotension. ${ }^{102}$

\section{End-tidal Carbon Dioxide}

The $\mathrm{ETCO}_{2}$ monitor is the most convenient and practical American Society of Anesthesiologists monitor used in the operating room, and critical importance must be paid to this monitor for a high-risk case.

A change of $2 \mathrm{mmHg} \mathrm{ETCO}_{2}$ can be an indicator of VAE. Therefore, the "low"-level alarm should be adjusted to detect even this small decrement, especially in high-risk procedures. ${ }^{104}$ Unfortunately, $\mathrm{ETCO}_{2}$ monitoring is not very specific, and its reliability in the event of systemic hypotension is difficult to assess. In addition, in spontaneously breathing patients, this monitor may become unreliable during periods of upper airway obstruction, mouth breathing, and variations in respiratory rate or obstruction of the gas analyzer port by mucus or condensation.

\section{Pulse Oximetry}

A change in oxygen saturation is a late finding of VAE and typically requires a severe physiologic disturbance because patients often are exposed to a high fraction of inspired oxygen during surgery. Transcutaneous oxygen 
and carbon dioxide are on the lower end of the sensitivity measurements.

\section{Vigilance of the Anesthesiologist}

As part of the comprehensive anesthetic management, timely anticipation of VAE during critical portions of a procedure is as vital to patient well-being as any detection device. For example, observing the absence of oozing venous blood from bone during removal of a craniectomy flap is indicative that the venous pressure at that level is less than the atmospheric pressure and poses a potential VAE risk.

\section{Esophageal Stethoscope}

The sensitivity of the esophageal stethoscope has been shown to be very low in detecting a mill wheel murmur $\left(1.7 \mathrm{ml} \cdot \mathrm{kg}^{-1} \cdot \mathrm{min}^{-1}\right) .{ }^{105}$

\section{Electrocardiographic Changes}

Alterations in the electrocardiogram rank low in sensitivity for VAE detection. Changes are seen early only with rapid entrainment of air, and generally reflect an already compromised cardiac status. Peaked $\mathrm{P}$ waves are the first change seen on a 12-lead electrocardiogram in animal studies. In humans, ST-T changes are noted first, followed by supraventricular and ventricular tachyarrythmias. $^{105}$

\section{Recommendation}

For routine surgical procedures where there is a low to moderate risk of venous air entrainment, such as spine procedures, abdominal explorations, and thoracotomies, the anesthesiologist should rely on vigilant monitoring of hemodynamic status, $\mathrm{ETCO}_{2}, \mathrm{ET}_{2}$ if available, and close visual inspection. During surgery that imposes a clear risk due to anticipated elevation of the surgical site with respect to the heart, laparoscopic procedures with anticipated vascular bleeding, or vascular abdominal cases (cesarean delivery), precordial Doppler ultrasound should be strongly considered in the anesthetic plan. It is the most cost effective, most easy to use, and least invasive of the sensitive monitoring devices. The use of transcranial Doppler or TEE requires special expertise and has not been demonstrated to provide significant additional clinical benefit over precordial Doppler.

\section{Prevention}

\section{Patient Positioning}

Improvements in technical capabilities have led to a dramatic decline in use of the sitting position in neurosurgical and orthopedic surgery. Alternative positioning such as prone or "park bench" provides adequate surgical conditions. Additional medical issues may impact on patient positioning. One such comorbidity is the patient with a documented right-to-left cardiac shunt via a patent foramen ovale. There seems to be an increased risk for a paradoxical embolus in the sitting position, although this has not been observed to lead directly to an increase in stroke or overall morbidity compared with nonsitting positions. ${ }^{106}$

Although near elimination of the sitting position has resulted in a substantial decline of catastrophic embolism, other perioperative scenarios continue to pose substantial threats of VAE. Common examples include the following:

Insertion and Removal of Central Venous Access Catheters. It is common to use the Trendelenburg position during the insertion of central venous catheters in the jugular or subclavian veins. Nevertheless, even using optimal positioning and techniques, air embolism has been reported ${ }^{65}$ in the interventional radiology literature at an incidence of $0.13 \%$ ( 15 episodes in 11,583 insertions). The criteria for confirmed VAE were such that only substantial volumes would have met the threshold: the hearing of audible suction or visualization of right ventricular air on fluoroscopy. One of the 15 patients died as a result of the embolism. In the authors' case series, the complication was commonly noted during insertion of a tunneled catheter through a peel-away sheath. ${ }^{65}$ This technique is frequently used in the operating room for insertion of hemodialysis access or the placement of portacaths. In such a scenario, it is common practice to stop ventilation during insertion of the finder needle to decrease the risk of a pneumothorax, especially with the subclavian site. Holding ventilation also reduces the negative intrathoracic pressure during the expiratory phase that may induce a suction effect, promoting VAE. Similarly, increasing right atrial pressure during the tunneling phase of catheter insertion may also minimize the risk of air entrainment.

Regarding placement and removal of the popular temporary, nontunneled catheters, it is important for providers to understand that the conditions that can increase the risk of air embolism include fracture or detachment of catheter connections, ${ }^{107,108}$ failure to occlude the needle hub or catheter during insertion or removal, dysfunction of self-sealing valves in plastic introducer sheaths, presence of a persistent catheter tract following removal, deep inspiration during insertion or removal (increases the magnitude of negative pressure within the thorax), hypovolemia (reduces central venous pressure), and upright positioning of the patient (reduces central venous pressure). Removal of the catheter should be synchronized with active exhalation if the patient is cooperative. If the patient is on mechanical ventilation, one can apply positive end-expiratory pressure. The Valsalva maneuver has proven to be superior to breath holding for increasing central venous pressure and may be beneficial to reduce the incidence of air entrainment in awake and cooperative patients. ${ }^{109}$ Pro- 
tective sheaths may aid in limiting contamination but seem to have limited value in prevention of VAE. ${ }^{110}$

Based on case report data, hospital safety-driven approaches toward development of protocols of central line care have been developed. ${ }^{111,112}$ The protocols emphasize incorporation of the Trendelenburg position during placement and removal of a central venous catheter. There are clinical situations where it may not be possible to have the patient in a Trendelenburg position for the duration of the procedure, as in the presence of increased intracranial pressure. In such circumstances, one may recommend transient Trendelenburg position during insertion of the guide wire or the catheter after the vein has been identified by the finder needle, and/or raising the legs by keeping pillows under the knees to increase the venous return and pressure in the right atrium. Debate exists as to whether the Trendelenburg position is necessary during catheter removal. ${ }^{113,114}$ Careful attention toward occlusion of the entry site may be most important.

Surgical Positioning. The anesthesiologist must be aware that surgery in the head-up position places the patient at risk for VAE. This may occur during craniotomy or spine procedures. However, the risk for VAE may also occur during shoulder surgeries and other procedures near the head and neck. In such situations, the propensity of incurring a negative gradient between the open site veins and the right atrium can be decreased by increasing right atrial pressure via leg elevation and using the "flex" option on the operating table control.

Cesarean Delivery. The traditional $15^{\circ}$ left lateral tilt position during cesarean deliveries creates a gradient between the right side of the heart, which is at a lower level than the uterus, thus encouraging air embolism. ${ }^{51}$ To counteract this, investigators have studied various positioning changes. In one report of patients undergoing cesarean deliveries, institution of a $5^{\circ}$ reverse Trendelenburg position was correlated with a VAE reduction from $44 \%$ to $1 \%$ in a series of 207 patients. ${ }^{52}$ Subsequently, data from one study comparing $5^{\circ}-10^{\circ}$ reverse Trendelenburg position found that the incidence of VAE is not affected..$^{53}$

The physiologic changes that occur during various patient positions must be anticipated, and strategies to minimize the negative gradient between the entraining vein and the right atrium must be adopted. Routine use of the Trendelenburg position or other methods of positioning (leg elevation) is recommended during insertion and removal of central venous catheters. Regarding positioning for cesarean delivery, conflicting data exist to recommend any alterations in positioning from common practice.

\section{Hydration}

An increased incidence of VAE has been reported in patients with a low central venous pressure, which en- hances the negative pressure gradient at the wound site compared to the right atrium. Hence, a well-hydrated patient reduces VAE risk. It has been proposed to maintain the right atrial pressure between 10 and $15 \mathrm{~cm} \mathrm{H}_{2} \mathrm{O}$, depending on the elevation of the patient. ${ }^{81} \mathrm{~A}$ useful maneuver is to zero the right atrial pressure at the level of the right atrium (fifth intercostal space in the midaxillary line) and then increase it to the level of the surgical site to assess whether a negative or positive gradient exists.

Regarding hydration, optimizing volume status should be adjusted to prevent wide gradients between the right atrium and the entraining vein, which may be guided by measurement of central venous pressure, along with other parameters of volume assessment such as respiratory variations in systolic blood pressure and urine output.

\section{Use of Military Antishock Trousers}

The use of military antishock trousers during surgery has been shown to increase right atrial pressure in the sitting position. It is possible to reliably sustain the right atrial pressure above atmospheric pressure by maintaining military antishock trouser pressure greater than 50 cm $\mathrm{H}_{2} \mathrm{O} .{ }^{115}$ The benefits of using military antishock trousers must be weighed against the risks of decreasing vital capacity, hypoperfusion to intraabdominal organs, and potential compartment syndromes.

Although the use of the military antishock trousers suit has been shown in one study to reliably elevate the right atrial pressures, its routine use in high-risk patients cannot be fully justified.

\section{Use of Positive End-expiratory Pressure}

The application of positive end-expiratory pressure (PEEP) has been controversial. Studies have demonstrated the safety of PEEP, ${ }^{115,116}$ and over wide ranges of positive pressure. ${ }^{117}$ Several investigations have shown it to be beneficial for prevention of VAE in both animal models and humans, but other reports suggest that PEEP potentially increased the risk of paradoxical air embolism, ${ }^{115}$ a fact exacerbated by a sudden release of positive pressure. ${ }^{118}$ Additional data suggest that application of PEEP does not reduce the incidence of VAE but leads to increased cardiovascular disturbance in the sitting position. ${ }^{119}$ Therefore, the role of PEEP during procedures at risk for VAE seems mixed. Because there are no definitive data to support the use of high PEEP $(>5 \mathrm{~cm}$ $\mathrm{H}_{2} \mathrm{O}$ ) as a prophylactic measure, and in some cases the risk of VAE increases, PEEP should be used with caution and used to improve oxygenation rather than as a means to minimize VAE.

\section{Avoidance of Nitrous Oxide}

Experimental and clinical investigations have demonstrated that in the presence of VAE, anesthesia with 
inhaled nitrous oxide in oxygen-air permits lower volumes of delivered venous gas to more rapidly exacerbate the hemodynamic effects of the embolism. ${ }^{120-123}$ This adverse effect is independent of whether the embolism occurs during open or laparoscopic procedures. In patients undergoing neurosurgical procedures in the prone position, there are data to suggest that nitrous oxide may actually be well tolerated. ${ }^{124}$ Nonetheless, nitrous oxide can dramatically increase the size of the entrained volume of air, being 34 times more soluble in blood than nitrogen.

It is also unclear, after a gas embolism has been diagnosed and the patient has been treated with $100 \%$ oxygen, at what point it is safe to begin nitrous oxide. Despite some data suggesting that air washout takes place within a relatively brief period of time $(60 \mathrm{~min}),{ }^{125}$ others suggest that nitrous oxide may be a problematic even if administered more than $2 \mathrm{~h}$ after institution of pure oxygen ventilation. ${ }^{126}$

Although without uniform consensus, there is ample data to discourage the use of nitrous oxide in any highrisk case. Any theoretical benefit nitrous oxide may contribute is unlikely to outweigh its potential adverse effects on VAE. In moderate- or low-risk procedures, the benefits of this agent should be weighed against the possible risks, and appropriate monitoring should be used.

\section{Management}

The diagnosis and subsequent management of VAE relies not only on a high index of suspicion, but also on newer sophisticated monitoring devices that enable early diagnosis and treatment before catastrophic cardiovascular collapse occurs. Principal goals of management where VAE is strongly suspected include prevention of further air entry; a reduction in the volume of air entrained, if possible; and hemodynamic support.

\section{Prevention of Further Air Entrainment}

Upon suspicion of VAE, the surgeon should be informed so as to immediately cover the surgical field with saline-soaked dressings, thus preventing further entrainment of air. The surgeon should then be asked to assess and to eliminate any entry site. The tilt of the operating table should be adjusted to lower the likely source of air entry and eliminate the negative air pressure gradient. For procedures below the level of the heart (i.e., lumbar spine, laparoscopy), placing the patient in a reverse Trendelenburg position, if tolerated, should be efficacious at reducing air entrainment.

If cranial surgery is being performed, air entrainment can be reduced by transient jugular venous compression, which by virtue of increasing venous pressure may identify open dural sinuses and result in retrograde flow.
Jugular venous compression has been shown in both animals $^{127,128}$ and humans ${ }^{129-131}$ to be effective in limiting the entry of air into the chest and the right atrium from sources in the face and head by increasing distal venous pressure, including the pressures recorded from incompressible veins such as the dural sinuses in humans. ${ }^{132}$ A direct consequence of this technique, and hence a severe limitation, is increase of intracranial pressure, thereby reducing cerebral perfusion. Additional concerns include direct carotid artery compression resulting in a decrease in cerebral blood flow and possible dislodgement of atheromatous plaque, venous engorgement leading to cerebral edema, and carotid sinus stimulation causing severe bradycardia.

\section{Institute High-flow Oxygen}

To maximize patient oxygenation during the period of cardiovascular instability, nitrous oxide should be discontinued, and the patient should be placed on $100 \%$ oxygen. This has the additional benefit of aiding elimination of nitrogen and reducing embolus volume. Clinical experience suggests that air may not clear rapidly after VAE and may remain susceptible to augmentation by nitrous oxide if reinstituted. ${ }^{126}$

\section{Reduce Embolic Obstruction}

It may be possible to relieve the air-lock in the right side of the heart either by placing the patient in a partial left lateral decubitus position (Durant maneuver), ${ }^{133}$ or simply placing the patient in the Trendelenburg position if the patient is hemodynamically unstable. Recent literature has questioned the Trendelenburg position as a favorable placement to optimize hemodynamics. ${ }^{134}$ The use of the traditional left lateral position has been found not to be beneficial in improving hemodynamic performance in canine studies. In fact, the concept of repositioning the patient at all during a suspected episode of VAE has been challenged in an animal study by Geissler et al. ${ }^{135}$ These investigators demonstrated that dogs in the left lateral position experienced no benefit during induced VAE, despite definitive relocation of air into the more nondependent portions of the heart. There are no data in humans, however.

\section{Cardiopulmonary Resuscitation and Chest Compressions}

Rapid initiation of cardiopulmonary resuscitation with defibrillation and chest compression has presumptively demonstrated efficacy for massive VAE that results in cardiac standstill. ${ }^{136}$ Even without need for cardiopulmonary resuscitation, the rationale behind closed-chest massage is to force air out of the pulmonary outflow tract into the smaller pulmonary vessels, thus improving forward blood flow. In canine studies, cardiac massage has been shown to be equally beneficial as left lateral posi- 
tioning and intracardiac aspiration of air, ${ }^{12}$ and there is substantiated clinical evidence of its efficacy. ${ }^{137}$

\section{Aspiration of Air from the Right Atrium}

Although intuitive, the success rates of appreciable aspiration of air during VAE are far from ideal. Multilumen catheters or Swan-Ganz catheters have been shown to be ineffective in aspirating air, with success rates between $6 \%$ and $16 \% .{ }^{138-143}$ The best available device probably is the Bunegin-Albin multiorifice catheter (Cook Critical Care (Bloomington, IN), with success rates as high as 30-60\%. ${ }^{139-141}$ The catheter (polyethylene, 5.8 French, 14-gauge size), can be inserted via the antecubital vein the subclavian or internal jugular veins, guided by either a chest $\mathrm{x}$-ray or an electrocardiogram lead that has been attached to the catheter (point of large negative $\mathrm{P}$ complex), positioned $2 \mathrm{~cm}$ distal to the superior vena caval-right atrial junction. ${ }^{143}$

In one of the earliest case reports, Stallworth et al. ${ }^{144}$ reported withdrawing $15 \mathrm{ml}$ of air from the right heart percutaneously in a case of venous air embolism, resulting in prompt hemodynamic improvement. This volume of air, $15-20 \mathrm{ml}$, has been the average amount that has been reported aspirated with a variety of devices during the past several decades. Currently, there are no data to support emergent catheter insertion for air aspiration during an acute setting of VAE-induced hemodynamic compromise.

\section{Hemodynamic Support}

The available literature discussing the hemodynamic treatment options in cases of VAE is limited. Clinical VAE increases right ventricular afterload, resulting in acute right ventricular failure and a subsequent decrease in left ventricular output. The logical management would be to optimize myocardial perfusion, relieve entrained air as possible, and provide inotropic support of the right ventricle. Jardin et al. ${ }^{145}$ used dobutamine in 10 patients with VAE-induced hemodynamic dysfunction treated and observed an increase in cardiac index and stroke volume while decreasing pulmonary vascular resistance. Dobutamine was started at $5 \mu \mathrm{g} \cdot \mathrm{kg}^{-1} \cdot \mathrm{min}^{-1}$, and the dose was increased by $5 \mu \mathrm{g} \cdot \mathrm{kg}^{-1} \cdot \min ^{-1}$ every $10 \mathrm{~min}$ until the desired effect was achieved. Archer et al. ${ }^{146}$ have described management of VAE with ephedrine.

The use of norepinephrine in the management of hypotension secondary to pulmonary embolism was studied in a canine model. ${ }^{147}$ Norepinephrine titrated to a modest increase in blood pressure produced significant improvement in ventricular performance without increasing pulmonary vascular resistance or compromising either renal blood flow or function.

\section{Hyperbaric Oxygen Therapy}

There have been numerous case reports and case series illustrating the potential benefits of hyperbaric oxygen therapy (HBO), especially in the presence of cerebral arterial gas embolism. The passage of the air into the pulmonary arterial circulation has been related to both the amount and the velocity of air infused or entrained. Animal data suggest that the lung acts as a physiologic filter, which becomes overwhelmed above $0.4 \mathrm{ml} \cdot \mathrm{kg}^{-1} \cdot \mathrm{min}^{-1} .{ }^{148}$

The physiologic derangements and the therapeutic interventions have been nicely detailed in two review articles. ${ }^{149,150}$ The proposed mechanisms of benefit of $\mathrm{HBO}$ are believed to be due to a reduction in the size of the air bubbles secondary to accelerated nitrogen resorption, and increased oxygen content of the blood. The size of the bubbles is inversely proportional to the ambient atmospheric pressure and, as the pressure increases to more than $1 \mathrm{~atm}$, the bubble size shrinks. ${ }^{151}$ Prospective trials demonstrating efficacy are lacking, however.

The optimal time from the occurrence of VAE to the start of therapy (range, 5-29 h) is also unclear. In a retrospective study of patients with venous or arterial embolism receiving HBO from 1980 to 1999 (86 patients), Blanc et al. ${ }^{152}$ noted that the benefits of $\mathrm{HBO}$ were clearly defined if this therapy was instituted within $6 \mathrm{~h}$ after the occurrence of venous air embolism. However, no benefit was noted in the arterial embolism group regardless of time to intervention. The authors concluded that $\mathrm{HBO}$ was ineffective if the embolism directly enters the cerebral circulation inducing ischemia. Although time may be a factor in the success of $\mathrm{HBO}$, there have been case reports of benefits using delayed $\left(>6 \mathrm{~h}\right.$ ) $\mathrm{HBO}$ therapy. ${ }^{153}$ Its use has proven effective independent of the cause of the embolism, and the number of sessions have varied anywhere from one $^{154}$ to nine (during nephrolithotripsy). ${ }^{155}$ The decision to pursue delayed $\mathrm{HBO}$ has been dependent on the amount of air entrained and the persistence of clinical signs. The risk of transportation of an unstable patient to a hyperbaric facility must be carefully considered.

\section{Experimental Therapies}

There has been substantial interest in the use of fluorocarbon derivatives in the management of the complications of VAE, particularly those of cerebral ischemia. All of the studies demonstrating benefits have been in animal models; human data are lacking.

Fluorocarbons are thought to enhance the reabsorption of bubbles and enhance the solubility of gases in blood. Studies conducted by Spiess et al. ${ }^{156}$ in the $1980 \mathrm{~s}$ demonstrated the fluorocarbon FP-43, which has 100,000 times solubility for oxygen, carbon dioxide, and nitrogen compared with plasma, would absorb air that was introduced into the circulation. This compound showed promising results in reducing the neurologic complications arising secondary to cardiopulmonary bypass and attributed to systemic air embolism. ${ }^{157}$ Infusion 


\section{Surgery or Invasive Vascular Procedure}

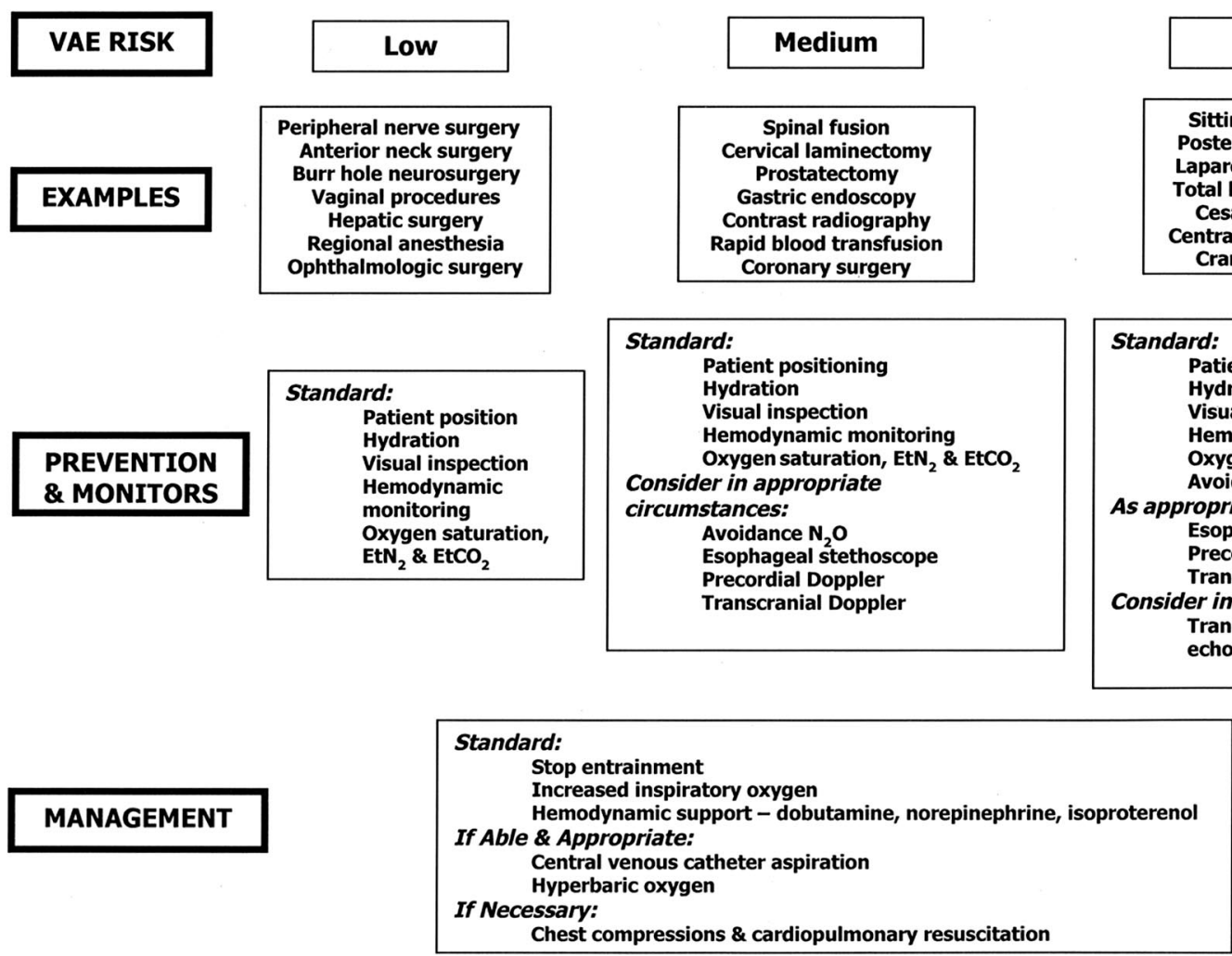

Fig. 2. Preventive measures, patient monitoring, and therapeutic management of vascular air embolism $(\mathrm{VAE})$. ETCO $2=\mathrm{end}-\mathrm{tidal}$ carbon dioxide; $\mathrm{ETN}_{2}=$ end-tidal nitrogen; $\mathrm{N}_{2} \mathrm{O}=$ nitrous oxide.

of FP-43 in dogs has also been shown do reduce the cardiovascular complications of coronary air embolism. ${ }^{158}$ Alterations in pulmonary artery pressure, arterial carbon dioxide tension, right ventricular stroke work index, and shunt fraction secondary to VAE are reduced by FP-43. ${ }^{159}$ In a more recent study, the use of the perfluorocarbon emulsion (OJSC SPC Perftoran; Moscow, Russia) decreased the bubble clearance time by $36 \%{ }^{160}$

\section{Clinical Recommendations}

The optimal management of VAE is prevention. Even after significant VAE, the greatest risk to the patient is continued entrainment of air. Preventive measures such as reducing the pressure gradient through repositioning, irrigating the field with fluid, intravascular volume loading, and use of moderate levels of PEEP remain important. Recognizing procedures at risk for VAE and planning the appropriate level of monitoring and management algorithms are key to patient safety (fig. 2).

The authors do not recommend routine continuous jugular venous compression in the initial management of VAE during cranial procedures. However, it may be considered on an emergent basis situations where high volume and rapid entrainment of air occurs. Compression of the external jugular vein for anterior scalp procedures is logical, but the majority of neck and scalp incidences of air embolism occur via the posterior venous complexes.

Attempts at aspiration of air from the right atrium seem prudent if a catheter is in place, and it is probably the only management strategy with demonstrated clinical efficacy. For catastrophic VAE with cardiovascular collapse, use of ionotropic support and, if necessary, cardiopulmonary resuscitation are standard measures that also may have a beneficial action in clearing residual air embolism. There is little evidence to support special patient positioning as a means to enhance air dispersion. If paradoxical cerebral air embolism occurs in a patient with stable hemodynamic and respiratory status, the consideration of HBO therapy is appropriate.

\section{Summary}

Vascular air embolism is a potentially life-threatening event that is increasingly more common in situations other than surgery performed in the classic sitting position. Clinicians must be aware of this silent but dangerous entity that can occur during many seemingly routine operative procedures and interventions. Unfortunately, there remains a paucity of prospective, controlled trials to assess various preventative and treatment options. 
Vascular air embolism may be detected by $\mathrm{ETCO}_{2}$ monitoring, and precordial Doppler ultrasound should be used in moderate- to high-risk patients undergoing highrisk procedures. Emphasis is given to the prevention (hydration, positioning) and prompt recognition of this event and to the use of all available tools (fluids, positive ionotropic agents) in the management of cardiovascular complications.

The use of invasive monitoring devices such as TEE and central venous catheters should be dictated by the presence of comorbidities, rather than as a primary tool to manage VAE. The use of hyperbaric oxygen is indicated depending on the severity and duration of the embolic sequelae, the presence of arterial embolism, and the availability of such a technique. Use of perfluorocarbons is an exciting new concept but has yet to be validated in humans.

\section{References}

1. Albin MS, Ritter RR, Reinhart R, Erickson D, Rockwood A: Venous air embolism during radical retropubic prostatectomy. Anesth Analg 1992; 74:151-3

2. Albin MS, Ritter RR, Pruett CE, Kalff K: Venous air embolism during lumbar laminectomy in the prone position: Report of three cases. Anesth Analg 1991; 73:346-9

3. Robinson DA, Albin MS: Venous air embolism and cesarean sections. ANEsTHESIOLOGY 1987; 66:93-4

4. Albin MS: Venous air embolism and lumbar disk surgery (letter). JAMA 1978; $240: 1713$

5. Oppenheimer MJ, Durant TM, Lynch P: Body position related to venous air embolism and associated cardiovascular-respiratory changes. Am J Med Sci 1953; 225:362-73

6. Alvaran SB, Toung JK, Graff TE, Benson DW: Venous air embolism: Comparative merits of external cardiac massage, intracardiac aspiration, and left lateral decubitus position. Anesth Analg 1978; 57:166-70

7. Munson E, Merrick HC: Effect of nitrous oxide on venous air embolism ANESTHESIOLOGY 1966; 27:783-7

8. Toung TJ, Rossberg MI, Hutchins GM: Volume of air in a lethal venous air embolism. Anesthesiology 2001; 94:360-1

9. Martland HS: Air embolism: Fatal air embolism due to powder insufflators used in gynecological treatments. Am J Surg 1945; 68:164-9

10. Flanagan JP, Gradisar IA, Gross RJ, Kelly TR: Air embolus: A lethal complication of subclavian venipuncture. N Engl J Med 1969; 281:488-9

11. Hybels RL: Venous air embolism in head and neck surgery. Laryngoscope 1980; 90:946-54

12. Takeoka M, Sakai A, Ueda G, Ge RL, Panos RJ, Taniguchi S: Influence of hypoxia and pulmonary air embolism on lung injury in perfused rat lungs. Respiration 1996; 63:346-51

13. Tanus-Santos JE, Gordo WM, Udelsmann A, Cittadino MH, Moreno H Jr: Nonselective endothelin-receptor antagonism attenuates hemodynamic changes after massive pulmonary air embolism in dogs. Chest 2000; 118:175-9

14. Kapoor T, Gutierrez G: Air embolism as a cause of the systemic inflammatory response syndrome: A case report. Critical Care 2003; 7:R98-100

15. Chandler WF, Dimcheff DG, Taren JA: Acute pulmonary edema following venous air embolism during a neurosurgical procedure: Case report. J Neurosurg 1974; 40:400-4

16. Holmes CM, Baker AB: Pulmonary edema associated with severe venous air embolism. Anaesth Intensive Care 1985; 13:4435-7

17. Lam KK, Hutchinson RC, Gin T: Severe pulmonary oedema after venous air embolism. Can J Anesth 1993; 40:964-7

18. Ishak BA, Seleny FL, Noah ZL: Venous air embolism, a possible cause of acute pulmonary edema. ANESTHESIOLOGY 1976; 45:453-5

19. Smelt WL, Baerts WD, de Langhe JJ: Pulmonary edema following air embolism. Acta Anesth Belg 1987; 38:201-5

20. Kuhn M, Fitting JW, Levenberger P: Acute pulmonary edema caused by venous air embolism after removal of a subclavian catheter. Chest 1987; 92: $364-5$

21. Hall ED: Neuroprotective actions of glucocorticoids and nonglucocorticoid steroids in acute neuronal injury. Cell Mol Neurobiol 1993; 13:415-32

22. Balki M, Manninen PH, McGuire GP, El-Behereiry H, Bernstein M: Venous air embolism during awake craniotomy in a supine patient. Can J Anesthesiol $2003 ; 50: 835-8$

23. Suarez S, Ornaque I, Fabregas N, Vlaero R, Carrero E: Venous air embolism during Parkinson surgery in patients with spontaneous ventilation. Anesth Analg 1999; 88:793-4

24. Harrison EA, Mackersie A, McEwan A, Facer E: The sitting position for neurosurgery in children: A review of 16 years' experience. Br J Anaesth 2002; 88:12-7

25. Bithal PK, Pandia MP, Dash HH, Chouhan RS, Mohanty B, Padhy N: Comparative incidence of venous air embolism and associated hypotension in adults and children operated for neurosurgery in the sitting position. Eur $\mathrm{J}$ Anaesthesiol 2004; 21:517-22

26. Losasso TJ, Black S, Muzzi DA, Michenfelder JD, Cucchiara RF: Detection and hemodynamic consequences of air embolism: Does nitrous oxide make a difference? ANESTHESIOLOGY 1992; 77:148-52

27. Papadopoulos G, Kuhly P, Brock M, Rudolph KH, Link J, Eyrich K: Venous and paradoxical air embolism in the sitting position: A prospective study with transesophageal echocardiography. Acta Neurochir (Wien) 1994; 126:140-3

28. Faberowski LW, Black S, Mickle JP: Incidence of venous air embolism during craniectomy for craniosynostosis repair. ANESTHESIOLOGY 2000; 92:20-3

29. Tobias JD, Johnson JO, Jimenez DF, Barone CM, McBride DS Jr: Venous air embolism during endoscopic strip craniectomy for repair of craniosynostosis in infants. Anesthesiology 2001; 95:340-2

30. Lopez LM, Traves N, Napal M: Fatal gas embolism during corrective surgery for scoliosis using the posterior approach. Rev Esp Anestesiol Reanim 1999; 46:267-70

31. Latson TW: Venous air embolism during spinal instrumentation and fusion in the prone position. Anesth Analg 1992; 75:152-3

32. Horlocker TT, Wedel DJ, Cucchiara RF: Venous air embolism during spinal instrumentation and fusion in the prone position (letter). Anesth Analg 1992; $75: 152$

33. McCarthy RE, Lonstein JE, Mertz JD, Kuslich SD: Air embolism in spinal surgery. J Spinal Disord 1990; 3:1-5

34. Frankel AS, Holzman RS: Air embolism during posterior spinal fusion. Can J Anaesth 1988; 35:511-4

35. Girard F, Ruel M, McKenty S, Boudreault D, Chouinard P, Todorov A, Molina-Negro P, Bouvier G: Incidences of venous air embolism and patent foramen ovale among patients undergoing selective peripheral denervation in the sitting position. Neurosurgery $2003 ; 53: 316-9$

36. Lobato EB, Black S, De Soto $\mathrm{H}$ : Venous air embolism and selective denervation for torticollis. Anesth Analg 1997; 84:551-3

37. Moitra V, Permut TA, Penn RM, Roth S: Venous air embolism in an awake patient undergoing placement of deep brain stimulators. J Neurosurg Anesthesiol 2004; 16:321-2

38. Deogaonkar A, Avitsian R, Henderson JM, Schubert A: Venous air embolism during deep brain stimulation surgery in an awake supine patient. Stereotact Funct Neurosurg 2005; 83:32-5

39. Longenecker CG: Venous air embolism during operations on the head and neck: Report of a case. Plast Reconstr Surg 1965; 36:619-21

40. Chang JL, Skolnick K, Bedger R, Schramm V, Bleyaert AL: Postoperative venous air embolism after removal of neck drains. Arch Otolaryngol 1981; 107:494-6

41. Ledowski T, Kiese F, Jeglin S, Scholz J: Possible air embolism during eye surgery. Anesth Analg 2005; 100:1651-2

42. Abu-Omar Y, Balacumaraswami L, Pigott DW, Matthews PM, Taggart DP: Solid and gaseous cerebral microembolization during off-pump, on-pump, and open cardiac surgery procedures. J Thorac Cardiovasc Surg 2004; 127:1759-65

43. Spiess BD, Sloan MS, McCarthy RJ, Lubenow TR, Tuman KJ, Matz SD, Ivankovich $\mathrm{AD}$ : The incidence of venous air embolism during total hip arthroplasty. J Clin Anesth 1988; 1:25-30

44. Sarantopoulos S, Lew J: Suspected case of venous air embolism in an infant undergoing hip arthrogram. Anaesth Intensive Care 2004; 32:423-5

45. Keidan I, Givon U, Berkenstadt H, Perel A: Venous air embolus during arthrography in a child: Vital signs changes illustrated by the automated data recording system. Paediatr Anaesth 2002; 12:362-4

46. Hetheringto RG, McQuillan PM: Venous air embolism during hip arthrography. Anesth Analg 1989; 69:264

47. Faure EA, Cook RI, Miles D: Air embolism during anesthesia for shoulder arthroscopy. ANESTHESIOLOGY 1998; 89:805-6

48. Diamond S, Kaplitz S, Novick O: Cerebral air embolism as a complication of thoracentesis. GP 1964; 30:87-91

49. Campbell PR, Kerridge R: Fatal traumatic air embolism following a stab wound to the chest. Aust N Z Surg 1993; 63:307-9

50. Gotz-Albrod S, Knuttgen D, Paul A: Arterial air embolism as a complication of blunt thoracic trauma. Anaesthesist 1999; 48:452-4

51. Lew TW, Tay DH, Thomas E: Venous air embolism during cesarean section: More common than previously thought. Anesth Analg 1993; 77:448-52

52. Fong J, Gadalla F, Druzin M: Venous emboli occurring caesarean section: The effect of patient position Can J Anaesth 1991; 38:191-5

53. Karuparthy VR, Downing JW, Husain FJ, Knape KG, Blanchard J, Solomon D, Albin MS: Incidence of venous air embolism during cesarean section is unchanged by the use of a 5 to 10 degree head-up tilt. Anesth Analg 1989; 69:620-3

54. Bloomstone J, Chow CM, Isselbacher E, VanCott E, Isaacson KB: A pilot study examining the frequency and quantity of gas embolization during operative 
hysteroscopy using a monopolar resectoscope. J Am Assoc Gynecol Laparosc 2002; 9:9-14

55. Imasogie N, Crago R, Leyland NA, Chung F: Probable gas embolism during operative hysteroscopy caused by products of combustion. Can J Anaesth 2002; 49:1044-7

56. Memtsoudis SG, Malhotra V: Catastrophic venous air embolus during prostatectomy in the Trendelenburg position. Can J Anaesth 2003; 50:1084-5

57. Jolliffe MP, Lyew MA, Berger IH, Grimaldi T: Venous air embolism during radical perineal prostatectomy. J Clin Anesth 1996; 8:659-61

58. Razvi HA, Chin JL, Bhandari R: Fatal air embolism during radical retropubic prostatectomy. J Urol 1994; 151:433-4

59. Derouin M, Couture P, Boudreault D, Girard D, Gravel D: Detection of gas embolism by transesophageal echocardiography during laparoscopic cholecystectomy. Anesth Analg 1996; 82:119-24

60. Scoletta P, Morsiani E, Ferrocci G, Maniscalco P, Pellegrini D, Colognesi A, Azzena G: Carbon dioxide embolization: Is it a complication of laparoscopic cholecystectomy? Minerva Chir 2003; 58:313-2

61. Bazin JE, Gillart T, Rasson P, Conio N, Aigouy L, Schoeffler P: Hemodynamic conditions enhancing gas embolism after venous injury during laparoscopy: A study in pigs. Br J Anaesth 1997; 78:570-5

62. Nayagam J, Ho KM, Liang J: Fatal systemic air embolism during endoscopic retrograde cholangio-pancreatography. Anaesth Intensive Care 2004; 32:260-4

63. Green BT, Tendler DA: Cerebral air embolism during upper endoscopy: case report and review. Gastrointest Endosc 2005; 61:620-3

64. Souron V, Fletcher D, Goujard E, Ecoffey C: Venous air embolism during orthotopic liver transplantation in a child. Can J Anesth 1997; 44:1187-90

65. Vesely TM: Air embolism during insertion of central venous catheters. J Vasc Interv Radiol 2001; 12:1291-5

66. Ely EW, Duncan HR: Venous air embolism from central venous catheterization: A need for increased physician awareness. Crit Care Med 1999; 27: 2113-7

67. Dube L, Soltner C, Daenen S, Lemariee J, Asfar P, Alquier P: Gas embolism An exceptional complication of radial arterial catheterization. Acta Anaesth Scand 2004; 48:1208-10

68. Laskey AL, Dyer C, Tobias JD: Venous air embolism during home infusion therapy. Pediatrics 2002; 109:E15

69. Panni MK, Camann W, Bhavani Shankar K: Hyperbaric therapy for a postpartum patient with prolonged epidural blockade and tomographic evidence of epidural air. Anesth Analg 2003; 97:1810-1

70. MacLean C, Bachman DT: Documented arterial gas embolism after spinal epidural injection. Ann Emerg Med 2001; 38:592-5

71. Woodring JH, Fried AM: Nonfatal venous air embolism after contrastenhanced CT. Radiology 1988; 167:405-7

72. Groell R, Schaffler GJ, Rienmueller R, Kern R: Vascular air embolism: Location, frequency, and cause on electron-beam CT studies of the chest. Radiology 1997; 202:459-62

73. Karaosmanoglu D, Oktar SO, Arac M, Erbas G: Case report: Portal and systemic venous gas in a patient after lumbar puncture. $\mathrm{Br} \mathrm{J}$ Radiol 2005; 78:767-9

74. Cruz-Flores S, Diamond AL, Leira EC: Cerebral air embolism secondary to intra-aortic balloon pump rupture. Neurocrit Care 2005; 2:49-50

75. Aldridge J: Potential air embolus from a Level 1 Rapid Infuser. Anaesthesia 2005; 6012:1250-1

76. Yeakel AE: Lethal air embolism from plastic blood-storage container. JAMA 1968; 204:267-9

77. Alper F, Kantarci M, Onbas O, Okur A, Ceviz N: Three-dimensional spiral CT reconstruction in a patient with massive cerebral air embolism. Emerg Radiol 2004; 11:87-8

78. Pham Dang C, Pereon Y, Champin P, Delecrin J, Passuti N: Paradoxical air embolism from patent foramen ovale in scoliosis surgery. Spine 2002; 27:E291-5

79. Kubo S, Nakata H: Air embolism due to a patent foramen ovale visualized by harmonic contrast echocardiography. J Neurol Neurosurg Psych 2001; 71:555

80. Heckmann JG, Lang CJ, Kindler K, Huk W, Erbguth EJ, Neundorfer B: Neurologic manifestations of cerebral air embolism as a complication of central venous catheterization. Crit Care Med 2000; 28:1621-5

81. Domaingue CM: Anaesthesia for neurosurgery in the sitting position: A practical approach. Anaesth Intensive Care 2005; 33:323-31

82. Domaingue CM: Neurosurgery in the sitting position: A case series. Anaesth Intensive Care 2005; 33:332-5

83. Cluroe AD: Delayed paradoxical air embolism following caesarian section for placenta previa: A case history. Pathology 1994; 26:209-11

84. Davies DE, Digwood KI, Hilton JN: Air embolism during caesarean section. Med J Aust 1980; 1:644-6

85. Lau WC, Fung HY, Rogers MS: Ten years experience of caesarean and postpartum hysterectomy in a teaching hospital in Hong Kong. Eur J Obstet Gynecol Reprod Biol 1997; 74:133-7

86. Kostash MA, Mensiink F: Lethal air embolism during cesarean delivery for placenta previa. ANESTHESIOLOGY 2002; 96:753-4

87. Root B, Levy MN, Pollack S, Lubert M, Pathak K: Gas embolism death after laparoscopy delayed by "trapping" in portal circulation. Anesth Analg 1978; 57:232-7

88. Handler JS, Bromage PR: Venous air embolism during cesarean delivery. Reg Anesth 1990; 15:170-3
89. Scoletta P, Morsiani E, Ferrocci G, Maniscalco P, Pellegrini D, Colognesi A, Azzena G: Carbon dioxide embolization: Is it a complication of laparoscopic cholecystectomy? [in Italian]. Minerva Chir 2003; 58:313-20

90. Landercasper J, Miller GJ, Strutt PJ, Olson RA, Boyd WC: Carbon dioxide embolization and laparoscopic cholecystectomy. Surg Laparosc Endosc 1993; 3:407-10

91. Souders JE: Pulmonary air embolism. J Clin Monit Comp 2000; 16:375-83 92. Jaffe RA, Siegel LC, Schnittger I, Propst JW, Brock-Utne JG: Epidural air injection assessed by transesophageal echocardiography. Reg Anesth 1995; 20: $152-5$

93. Furuya H, Suzuki T, Okumura F, Kishi Y, Uefuji T: Detection of air embolism by transesophageal echocardiography. ANESTHESIOLOGY 1983; 58:124-9

94. Himmelseher S, Pfenninger E, Werner C: Intraoperative monitoring in neuroanesthesia: A national comparison between two surveys in Germany in 1991 and 1997. Scientific Neuroanesthesia Research Group of the German Society of Anesthesia and Intensive Care Medicine. Anesth Analg 2001; 92: 166-71

95. Chang JL, Albin MS, Bunegin L, Hung TK: Analysis and comparison of venous air embolism detection methods. Neurosurgery 1980; 7:135-41

96. Soriano SG, McManus ML, Sullivan LJ, Scott RM, Rockoff MA: Doppler sensor placement during neurosurgical procedures for children in the prone position. J Neurosurg Anesthesiol 1994; 6:153-5

97. Boussuges A, Molenat F, Carturan D, Gerbeaux P, Sainty JM: Venous gas embolism: Detection with pulsed Doppler guided by two-dimensional echocardiography. Acta Anaesthesiol Scand 1999; 43:328-32

98. Stendel R, Gramm HJ, Schroder K, Lober CS, Brock M: Transcranial Doppler ultrasonography as a screening technique for detection of a patent foramen ovale before surgery in the sitting position. ANesthesIology 2000; 93: 971-5

99. Klotzsch C, Janssen G, Berlit P: Transesophageal echocardiography and contrast-TCD in the detection of a patent foramen ovale: Experiences with 111 patients. Neurology 1994; 44:1603-6

100. Volk O, Schnitker W, Brass P, Klass O, Bosse M, Boerner U, Fischer JH, Schregel W: Detection of air embolism by a re-usable Doppler probe integrated in a central venous line: Application in vivo. Anesthetist 2002; 51:716-20

101. Matjasko J, Petrozza P, Cohen M, Steinberg P: Anesthesia and surgery in the seated position: Analysis of 554 cases. Neurosurgery 1985; 17:695-702

102. Matjasko J, Petrozza P, Mackenzie CF: Sensitivity of end-tidal nitrogen in venous air embolism detection in dogs. ANESTHESIOLOGY 1985; 63:418-23

103. Drummond JC, Prutow RJ, Scheller MS: A comparison of the sensitivity of pulmonary artery pressure, end-tidal carbon dioxide, and end-tidal nitrogen in the detection of venous air embolism in the dog. Anesth Analg 1985; 64:688-92

104. Brechner TM, Brechner VL: An audible alarm for monitoring air embolism during neurosurgery. J Neurosurg 1977; 47:201-4

105. Gildenberg PL, O'Brie RP, Britt WJ, Frost EA: The efficacy of Doppler monitoring for the detection of venous air embolism. J Neurosurg 1981; 54:75-8

106. Mammoto T, Hayashi Y, Ohnishi Y, Kuro M: Incidence of venous and paradoxical air embolism in neurosurgical patients in the sitting position: Detection by transesophageal echocardiography. Acta Anaesthesiol Scand 1998; 42: $643-7$

107. Peter DA, Saxman C: Preventing air embolism when removing CVCs: An evidence-based approach to changing practice. Medsurg Nursing 2003; 12:223-8

108. Brouns R, De Surgeloose D, Neetens I, De Deyn PP: Fatal venous cerebral air embolism secondary to a disconnected central venous catheter. Cerebrovasc Dis 2006; 21:212-4

109. Kolbeck KJ, Itkin M, Stravropoulos SW, Trerotola SO: Measurement of air emboli during central venous access: Do "protective" sheaths or insertion techniques matter? J Vasc Interv Radiol 2005; 16:89-99

110. Pronovost PJ, Wu AW, Sexton B: Acute decompensation after removing a central line: Practical approaches to increasing safety in the intensive care unit. Ann Intern Med 2004; 140:1025-33

111. Andrews CM: Preventing air embolism. Am J Nurs 2002; 102:34-6

112. Sing RF, Thomason MH, Heniford BT, Miles WS, Huynh TT, Jacobs DG, Lipford EH: Venous air embolism from central venous catheterization: Underrecognized or over-diagnosed? Crit Care Med 2000; 28:3377-8

113. Brederlau J, Greim C, Schwemmer U, Haunschmid B, Markus C, Roewer $\mathrm{N}$ : Ultrasound-guided cannulation of the internal jugular vein in critically ill patients positioned in 30 degrees dorsal elevation. Eur J Anaesthesiol 2004; 21:684-7

114. Wysoki MG, Covey A, Pollak J, Rosenblatt M, Aruny J, Denbow N: Evaluation of various maneuvers for prevention of air embolism during central venous catheter placement. J Vasc Interv Radiol 2001; 12:764-6

115. Meyer PG, Cuttaree H, Charron B, Jarreau MM, Peri AC, Sainte-Rose C: Prevention of venous air embolism in paediatric neurosurgical procedures performed in the sitting position by combined use of MAST suit and PEEP. Br J Anaesth 1994; 73:795-800

116. Perkins NA, Bedford RF: Hemodynamic consequences of PEEP in seated neurological patients: Implications for paradoxical air embolism. Anesth Analg 1984; 63:429-32

117. Zasslow MA, Pearl RG, Larson CP, Silverberg G, Shuer LF: PEEP does not affect left atrial-right atrial pressure difference in neurosurgical patients. ANESTHESIOLOGY 1988; 68:760-3

118. Schmitt HJ, Hemmerling TM: Venous air emboli occur during release of 
positive end-expiratory pressure and repositioning after sitting position surgery. Anesth Analg 2002; 94:400-3

119. Giebler R, Scherer R, Erhard J: Effect of positive end-expiratory pressure on the incidence of venous air embolism and on the cardiovascular response to the sitting position during neurosurgery. Br J Anaesth 1998; 80:30-5

120. Junghans T, Bohm B, Meyer E: Influence of nitrous oxide anesthesia on venous gas embolism with carbon dioxide and helium during pneumoperitoneum. Surg Endosc 2000; 14:1167-70

121. Kytta J, Tanskanen P, Randell T: Comparison of the effects of controlled ventilation with $100 \%$ oxygen, $50 \%$ oxygen in nitrogen, and $50 \%$ oxygen in nitrous oxide on responses to venous air embolism in pigs. Br J Anaesth 1996; 77:658-61

122. Steffey EP, Johnson BH, Eger EI II: Nitrous oxide intensifies the pulmonary arterial pressure response to venous injection of carbon dioxide in the dog. ANESTHESIOLOGY 1980; 52:52-5

123. Nyarwaya JB, Pierre S, Mazoit JX, Umbrain V, Romain M, Samii K, d'Hollander A: Effects of carbon dioxide embolism with nitrous oxide in the inspired gas in piglets. Br J Anaesth 1996; 76:428-34

124. Losasso TJ, Muzzi DA, Dietz NM, Cucchiara RF: Fifty percent nitrous oxide does not increase the risk of venous air embolism in neurosurgical patients operated upon in the sitting position. ANESTHESIOLOGY 1992; 77:21-30

125. Shapiro HM, Yoachim J, Marshall LF: Nitrous oxide challenge for detection of residual intravascular pulmonary gas following venous air embolism. Anesth Analg 1982; 61:304-6

126. Sibai AN, Baraka A, Moudawar A: Hazards of nitrous oxide administration in presence of venous air embolism. Middle East J Anesthesiol 1996; 13:565-71

127. Toung TJ, Miyabe M, McShane AJ, Rogers MC, Traystman RJ: Effect of PEEP and jugular venous compression on canine cerebral blood flow and oxygen consumption in the head elevated position. Anesthesiology 1988; 68:53-8

128. Pfitzner J, McLean AG: Controlled neck compression in neurosurgery: Studies on venous air embolism in upright sheep. Anaesthesia 1985; 40:624-9

129. Grady MS, Bedford RF, Park TS: Changes in superior sagittal sinus pressure in children with head elevation, jugular venous compression, and PEEP. J Neurosurg 1986; 65:199-202

130. Losasso TJ, Muzzi DA, Cucchiara RF: Jugular venous compression helps to identify the source of venous air embolism during craniectomy in patients in the sitting position. ANesthesiology 1992; 76:156-7

131. Takahashi T, Yano K, Kimura T, Komatsu T, Shimada Y: Prevention of venous air embolism by jugular venous compression under superior sagittal sinus pressure monitoring in a brachycephalic patient during craniofacial reconstruction. Paediatr Anaesth 1997; 7:259-60

132. Iwabuchi T, Sobata E, Ebina K, Tsubakisaka H, Takiguchi M: Dural sinus pressure: Various aspects in human brain surgery in children and adults. Am J Physiol 1986; 250:H389-96

133. Durant TM, Long J, Oppenheimer MJ: Pulmonary (venous) air embolism Am Heart J 1947; 33:269-81

134. Mehlhorn U, Burke EJ, Butler BD, Davis KL, Katz J, Melamed E, Morris WP, Allen SJ: Body position does not affect the hemodynamic response to venous air embolism in dogs. Anesth Analg 1994; 79:734-9

135. Geissler HJ, Allen SJ, Mehlhorn U, Davis KL, Morris WP, Butler BD: Effect of body repositioning after venous air embolism: An echocardiographic study. ANESTHESIOLOGY 1997; 86:710-7

136. Ericsson JA, Gottlieb JD, Sweet RB: Closed-chest cardiac massage in the treatment of venous air embolism. N Engl J Med 1964; 270:1353-4

137. Yeh PA, Chen HP, Tsai YC, Lin YJ, Liu YC: Successful management of air embolism-induced ventricular fibrillation in orthotopic liver transplantation. Acta Anaesthesiol Taiwan 2005; 43:243-6

138. Artru AA: Venous air embolism in prone dogs positioned with the abdomen hanging freely: Percentage of gas retrieved and success rate of resuscitation. Anesth Analg 1992; 75:715-9

139. Colley PS, Artru AA: Bunegin-Albin catheter improves air retrieval and resuscitation from lethal venous air embolism in upright dogs. Anesth Analg 1989; 68:298-301

140. Bowdle TA, Artru AA: Treatment of air embolism with a special pulmonary artery catheter introducer sheath in sitting dogs. ANESTHESIOLOGY 1988; 68:107-10

141. Colley PS, Artru AA: Bunegin-Albin catheter improves air retrieval and resuscitation from lethal venous air embolism in dogs. Anesth Analg 1987; 66:991-4

142. Bedford RF, Marshall WK, Butler A, Welsh JE: Cardiac catheters for diagnosis and treatment of venous air embolism. J Neurosurg 1981; 55:610-4

143. Hanna PG, Gravenstein N, Pashayan AG: In vitro comparison of central venous catheters for aspiration of venous air embolism: Effect of catheter type, catheter tip position, and cardiac inclination. J Clin Anesth 1991; 3:90-4

144. Stallworth JM, Martin JB, Postlethwait RW: Aspiration of the heart in air embolism. J Am Med Assoc 1950; 143:1250-1

145. Jardin F, Genevray B, Brun-Ney D, Margairaz A: Dobutamine: A hemodynamic evaluation in pulmonary embolism shock. Crit Care Med 1985; 13:1009-12

146. Archer DP, Pash MP, MacRae ME: Successful management of venous air embolism with inotropic support. Neuroanesth Intensive Care 2001; 48:204-8

147. Angle MR, Molloy DW, Penner B, Jones D, Prewitt RM: The cardiopulmonary and renal hemodynamic effects of norepinephrine in canine pulmonary embolism. Chest 1989; 95:1333-7

148. Butler BD, Hills BA: Transpulmonary passage of venous air emboli. J Appl Physiol 1985; 59:543-7

149. Van Hulst RA, Klein J, Lachmann B: Gas embolism: Pathophysiology and treatment. Clin Physiol Fun Imag 2003; 23:237-46

150. Muth CM, Shanck E: Gas embolism. N Engl J Med 2000; 342:476-82

151. Dexter F, Hindman BJ: Recommendations for hyperbaric oxygen therapy of cerebral air embolism based on a mathematical model of bubble absorption. Anesth Analg 1997; 84:1203-7

152. Blanc P, Boussuges A, Henriette K, Sainty JM, Deleflie M: Iatrogenic cerebral air embolism: Importance of an early hyperbaric oxygenation. Intensive Care Med 2002; 28559-63

153. Mader JT, Hulet WH: Delayed hyperbaric treatment of cerebral air embolism. Arch Neurol 1979; 36:504-5

154. Benson J, Adkinson C, Collier R: Hyperbaric oxygen therapy of iatrogenic cerebral arterial gas embolism. Undersea Hyperb Med 2003; 30:117-26

155. Droghetti L, Giganti M, Memmo A, Zatelli R: Air embolism: Diagnosis with single-photon emission tomography and successful hyperbaric oxygen therapy. Br J Anaesth 2002; 89:775-8

156. Spiess BD, McCarthy R, Piotrowski D, Ivankovich AD: Protection from venous air embolism with fluorocarbon emulsion FC-43. J Surg Res 1986; 41: 439-44

157. Cochran RP, Kunzelman KS, Vocelka CR, Akimoto H, Thomas R, Soltow LO, Spiess BD: Perfluorocarbon emulsion in the cardiopulmonary bypass prime reduces neurologic injury. Ann Thorac Surg 1997; 63:1326-32

158. Spiess BD, McCarthy RJ, Tuman KJ, Ivankovich AD: Protection from coronary air embolism by a perfluorocarbon emulsion (FC-43). J Cardiothorac Anesth $1987 ; 1: 210-5$

159. Tuman KJ, Spiess BD, McCarthy RJ, Ivankovich AD: Cardiorespiratory effects of venous air embolism in dogs receiving a perfluorocarbon emulsion. $\mathrm{J}$ Neurosurg 1986; 65:238-44

160. Eckmann DM, Lomivorotov VN: Microvascular gas embolization clearance following perfluorocarbon administration. J Appl Physiol 2003; 94:860-8 